\title{
Initial prediction of dust production in pebble bed reactors
}

\author{
M. Rostamian ${ }^{1}$, S. Arifeen ${ }^{2}$, G. P. Potirniche ${ }^{2}$, and A. Tokuhiro ${ }^{1}$ \\ ${ }^{1}$ Department of Mechanical Engineering, University of Idaho, 1776 Science Center Dr, Idaho Falls, ID, USA \\ ${ }^{2}$ Department of Mechanical Engineering, University of Idaho, 440902 Moscow, ID, 83844-0902, USA
}

Received: 24 June 2011 - Revised: 23 August 2011 - Accepted: 24 August 2011 - Published: 30 September 2011

Abstract. This paper describes the computational simulation of contact zones between pebbles in a pebble bed reactor. In this type of reactor, the potential for graphite dust generation from frictional contact of graphite pebbles and the subsequent transport of dust and fission products can cause significant safety issues at very high temperatures around $900^{\circ} \mathrm{C}$ in HTRs. The present simulation is an initial attempt to quantify the amount of nuclear grade graphite dust produced within a very high temperature reactor.

\section{Introduction}

The gas-cooled graphite-moderated pebble bed reactor is a leading concept for the Next Generation Nuclear Plant, a Very High Temperature Reactor (VHTR) under consideration in the US. In the proposed reactor, spherical graphite pebbles (Fig. 1) are used as fuel elements. These graphite pebbles contain thousands of tristructural-isotropic (TRISO) fuel particles which are mainly made of enriched uranium. The graphite pebbles are inserted into the reactor from the top and they move downward due to gravity to reach the outlet chute where they go through burnup assay or fuel utilization. Here, the burnup limit of graphite pebbles is assessed to determine if they are to be recirculated or stored in the storage tank.

In VHTRs, the potential graphite dust generation is caused by several sources. These sources are pebble-pebble contact, pebble-wall contact, fuel handling which proceeds burnup assay and oxidation from impurities present in the helium coolant (Cogliati and Ougouag, 2008).

There are many disadvantages to dust production at very high temperatures in pebble bed reactors (PBR). In the presence of graphite dust, helium can become radioactive, reducing the efficiency of heat exchangers (Cogliati and Ougouag, 2010). In direct cycle HTGRs, the generated graphite particulates collide with turbine blades and can considerably decrease their service life (Cogliati and Ougouag, 2010). The amount of graphite dust generated is a key input for design safety review (US Nuclear Regulatory Commission, 2008; IAEA, 2003). The only previous prediction of dust production was made for the German Arbeitsgemeinschaft Versuchsreaktor (AVR), which was around $3 \mathrm{~kg} \mathrm{yr}^{-1}$ (Xiaowei et al., 2005).

\section{Computational model}

In the present work, the simulations of pebble contact were conducted using the finite element software ABAQUS (ABAQUS FEA, 2010) to predict an initial estimate for PBR graphite dust production.

Two different configurations are considered: (1) two Quarter Spheres in contact (QS) model illustrated in Fig. 2a, and (2) a Body Centered Cubic (BCC) model 1 , in one pebble is in contact with eight other ones, as shown in Fig. 2b. The QS model is a simple model to start performing simulations but the $\mathrm{BCC}$ model is a more realistic configuration which better represents the conditions of pebbles in a PBR (du Toit et al., 2009).

Two types of simulations are also considered: (1) static simulations where pebble-pebble forces and friction at contact points are considered without pebble movements with respect to each other, and (2) dynamic simulations, where pebble-pebble forces, friction at contact points and rotation of the center pebble with respect to the neighboring ones is considered. 


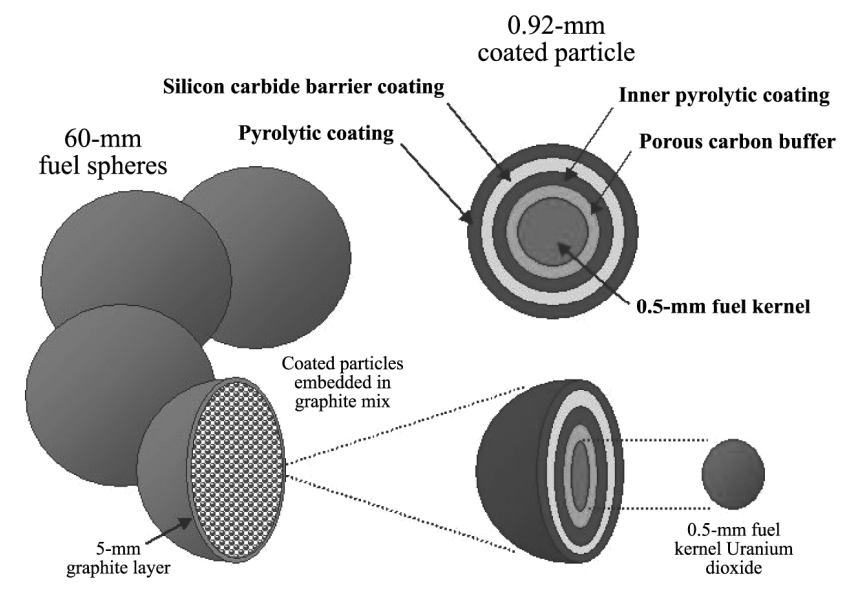

Figure 1. Graphite Fuel Elements in PBRs (Schaffer, 2007).

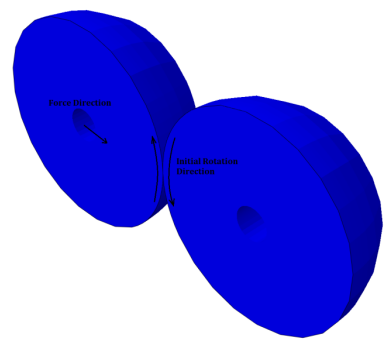

(a)

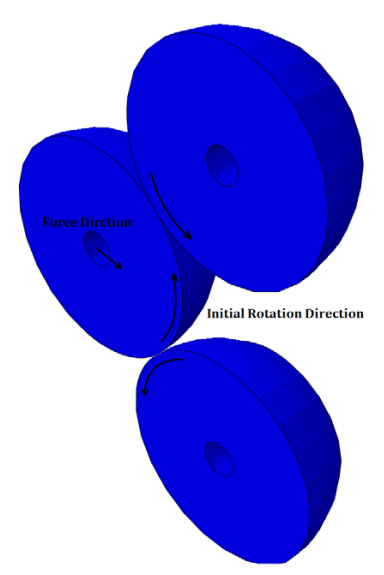

(b)

Figure 2. QS (a) and BCC (b) configurations. Symmery conditions are imposed.

The material properties were modeled by considering an elastoplastic stress-strain behavior coupled with ductile damage effects. A mesh refinement was considered to determine the number of elements with damage values exceeding a minimum predetermined value. The extent of damage was used to determine the amount of mass removed. Finally, the results are discussed and compared with previous works (Cogliati and Ougouag, 2010; Xiaowei et al., 2005).

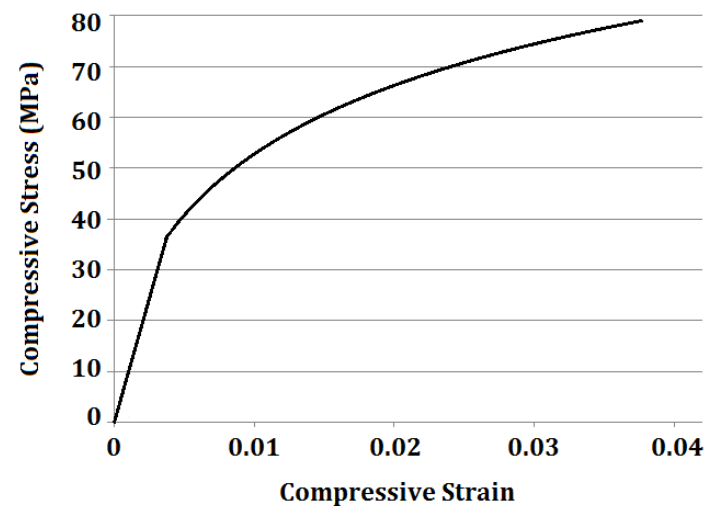

Figure 3. Stress-strain curve for IG-11.

Table 1. Isotrpic plastic model data.

\begin{tabular}{cc}
\hline Yield Stress (MPa) & Plastic Strain \\
\hline 45005500 & 0 \\
48779700 & 0.0015747 \\
53811900 & 0.0040155 \\
58765500 & 0.0066925 \\
63247300 & 0.0099206 \\
67414600 & 0.0136999 \\
71739100 & 0.0185028 \\
74962900 & 0.0230694 \\
77557600 & 0.0271636 \\
79287400 & 0.0309429 \\
\hline
\end{tabular}

\subsection{Material properties}

The nuclear grade graphite IG-11 with elastoplastic behavior at the strain rate of $0.0011 \mathrm{~s}^{-1}$ is considered to determine the extent of pebble damage due to contact and wear forces (Fig. 3 and Table 1).

\subsection{Isotropic elastic model}

From the stress-strain diagram shown in Fig. 3, the elastic properties are derived. The Young's modulus and yield stress are found to be $E=9.8 \mathrm{GPa}$. The Poisson ratio is also known to be 0.126 for this nuclear grade graphite (Yokoyama et al., 2008).

\subsubsection{Isotropic plastic model}

From the plastic portion of this stress-strain curve, the yield stress and the corresponding plastic strain are derived. The plastic stress-strain data input for ABAQUS to replica is shown in Table 1. 
Table 2. Damage model data.

\begin{tabular}{ccc}
\hline $\begin{array}{c}\text { Fracture } \\
\text { Strain }\end{array}$ & $\begin{array}{c}\text { Stress } \\
\text { Triaxiality }\end{array}$ & $\begin{array}{c}\text { Strain Rate } \\
\text { (Yokoyama et al., 2008) }\end{array}$ \\
\hline 0.0448246 & 0.333 & $0.0011 \mathrm{~s}^{-1}$ \\
\hline
\end{tabular}

\subsubsection{Ductile damage model}

A ductile damage criterion (Johnson and Cook, 1985) is used in this numerical simulation. The fracture strain (at specific strain rate) and stress triaxiality are needed to set this criterion. Once this limit is exceeded, elements are capable of being removed from the surface of the contact point. In this study, the damage is investigated macroscopically and IG-11 is considered as a continuous homogenous material.

In Table 2 stress triaxiality is simply found to be 0.333 because of material homogeneity in three directions.

\subsection{Model setup}

The simulation setup consists of two sections with two models for pebble-pebble contact the QS model and the BCC model unit cell configuration. The latter represents a more realistic configuration of a pebble condition in contact with eight other ones.

\subsubsection{QS Model}

In this model, two quarter spheres are in contact and the boundary conditions and loads are set as illustrated in Fig. 4 . In this figure, $u$ represents translational velocity in $\mathrm{m} \mathrm{s}^{-1}$ and $u r$ represents rotational velocity in radians.

\subsubsection{BCC Model}

In this model, one quarter sphere is in contact with two eightspheres representing a portion of a unit cell model, which is cut at its symmetrical planes. The boundary conditions and loads are set as in Fig. 5. In this figure, the model is reduced by considering the existing symmetry in the BCC configuration.

\subsection{Simulation setup}

The simulations are also carried out in two phases. A static simulation is performed where stationary pebblepebble forces and friction at contact points are considered. In the static simulations, due to the linearity of the simulations, ABAQUS/Standard module has been implemented.

The boundary conditions, loads and constrains are illustrated in Figs. 4a and 5a.

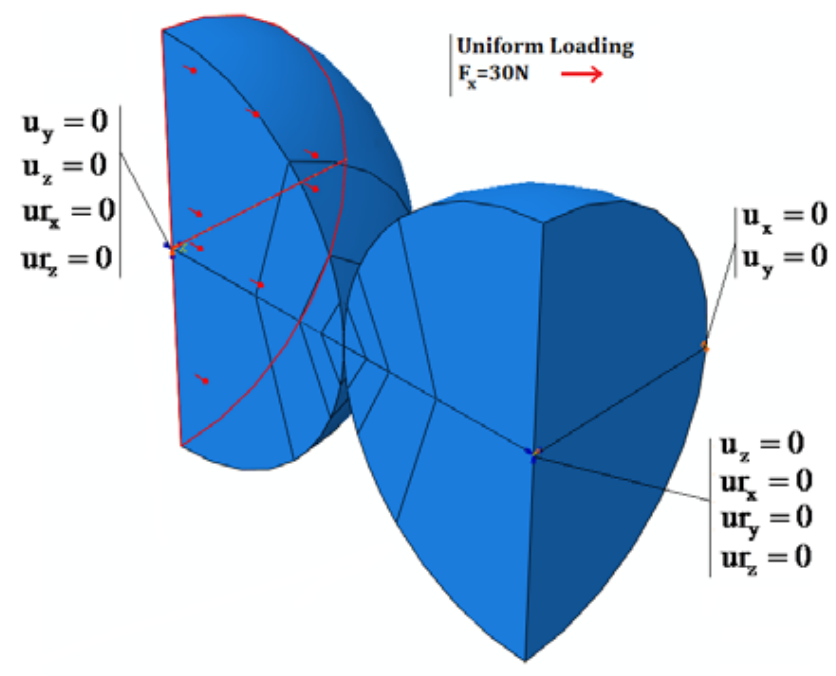

(a)

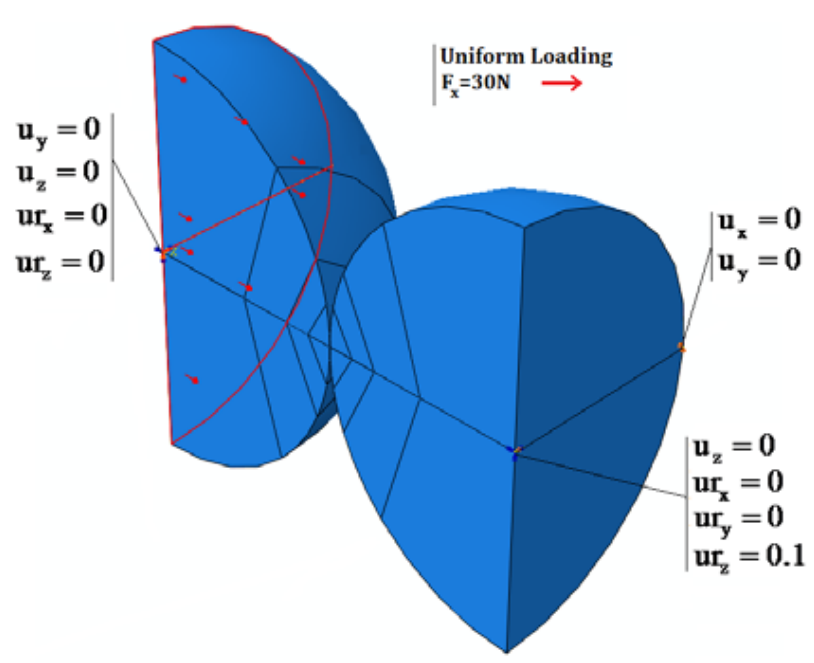

(b)

Figure 4. QS model boundary conditions and loads in static (a) and dynamic (b) phases (rotation in radians).

The dynamic simulation considers pebble-pebble forces, friction at contact points and rotation of the center pebble. In the dynamic simulations, ABAQUS/Explicit module has been implemented to handle the nonlinearities caused by rotational velocity and contact mechanics. The boundary conditions, loads and constrains are illustrated in Figs. $4 \mathrm{~b}$ and $5 \mathrm{~b}$. 


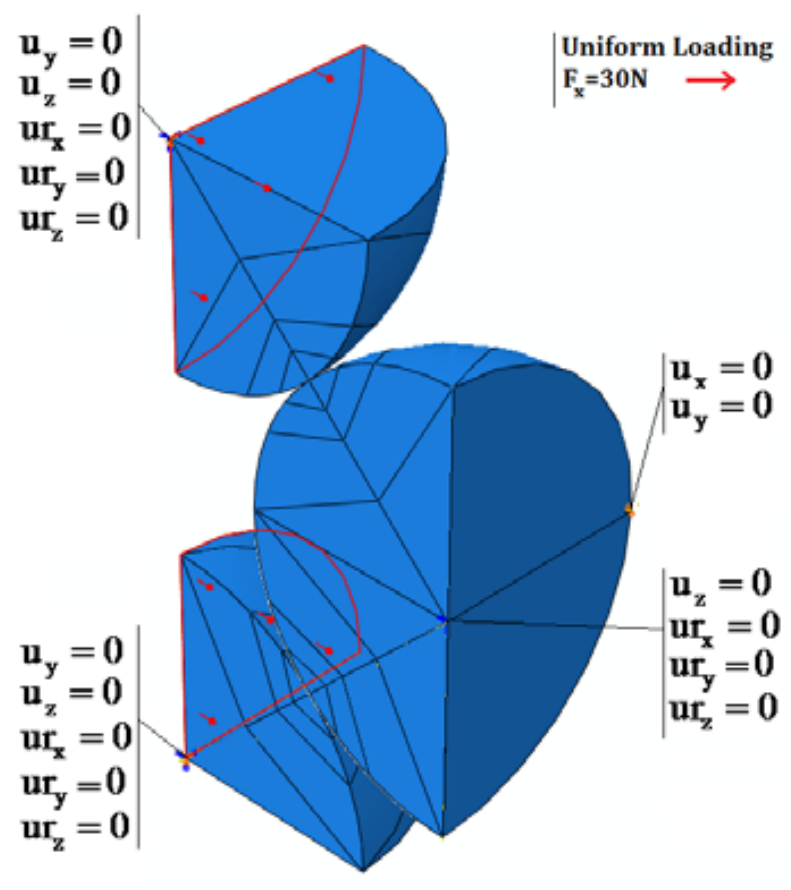

(a)

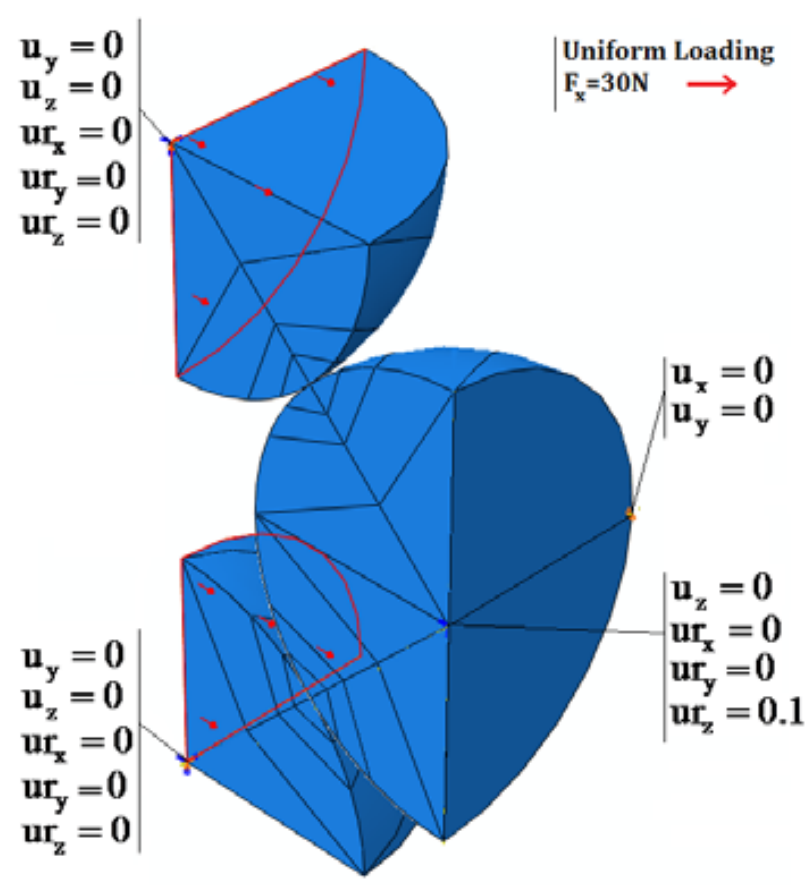

(b)

Figure 5. BCC model boundary conditions and loads in static (a) and dynamic (b) phases (rotation in radians).

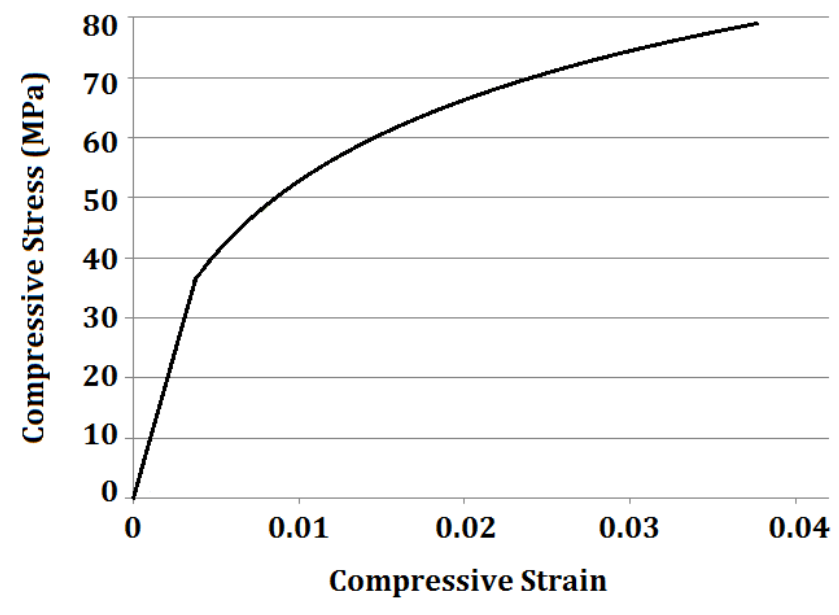

Figure 6. Mesh refinement study results: the optimum element size and stress.

\subsection{Mesh refinement study}

Considering the elastic model, simulations were run for different element sizes to perform a mesh refinement study (MRS); the MRS led to the optimal element size of $0.022 \mathrm{~cm}$ for the contact zone (Fig. 6).

This optimal element size helps reduce computational costs and time. The optimum mesh as identified from the MRS results in the optimal refinement of mesh in the contact zone, where results are sensitive to element size. Figure 6 presents the optimal mesh near the contact zone.

\section{Results and discussions}

In this section, first the von Mises stress contours and damage contours are illustrated and discussed briefly. Finally, an estimate of the mass removal from the surface of graphite pebbles is discussed.

\subsection{Static simulation results}

As seen in Fig. 7, in both configurations higher stresses are experiences at the tip of the contact area than those at the center-point. This is due to the deflection at the tip of the contact area which is itself a flat circle-shaped region perpendicular to the figure plain.

As seen in Fig. 8, higher damage is at the edges of the contact area due to higher local deformations.

\subsection{Dynamic simulation results}

As seen in Fig. 9, in both models higher stresses are experiences at the tip of the contact area than that at the centerpoint. This is due to the deformation at the tip of the contact area. 


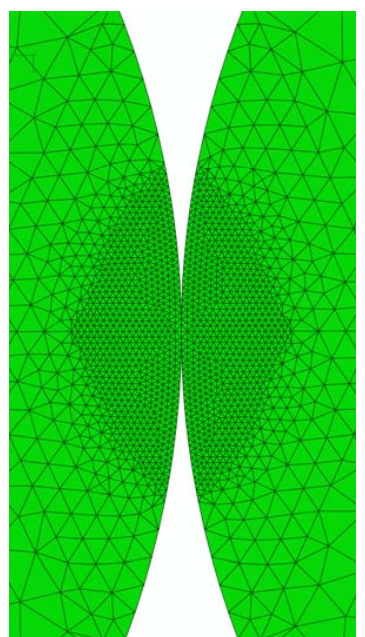

(a)

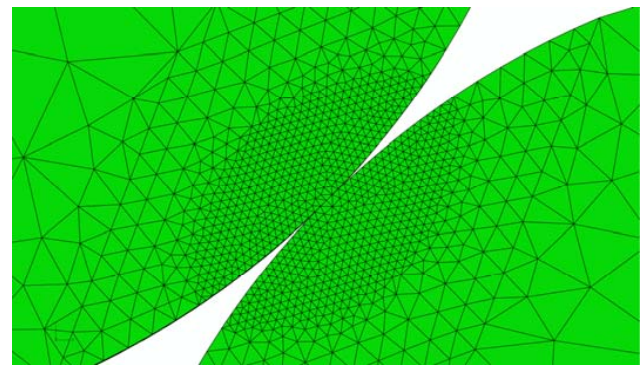

(b)

Figure 7. Contact zone refined mesh for (a) the QS and (b) BCC models.

Note that, in the dynamic simulation, the damaged zones are not completely facing each other due to the axial rotation of one pebble against the other.

As seen in Figs. 10 and 11, higher stress and damage are experienced at the edges of the contact area due to higher local deformations.

The contact zone is a circular area which is perpendicular to the figure plains whose upper and lower edges experience high stresses and therefore high damages.

\section{Dust mass prediction}

Based on the damage results, by probing the elements in the damaged region and tallying the damage criterion at each damaged element, the number of elements that were capable of removal due to excessive damage was counted and therefore an estimate of the mass removal was predicted.

In the Static simulation, no elements passed the damage criterion in the QS model and as a result the mass removal estimate was predicted to be zero; while in the static BCC model given the density of $1.77 \mathrm{~g} \mathrm{~cm}^{-3}$ (Yoda and Eto, 1983), an estimate of $5.9 \mathrm{~g} \mathrm{yr}^{-1}$ was predicted.

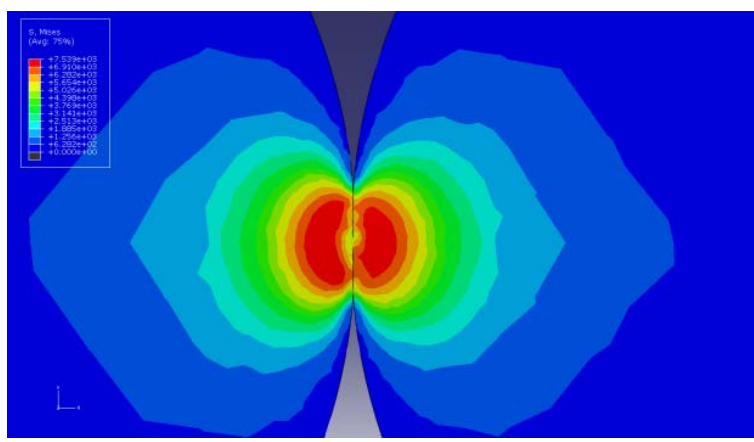

(a)

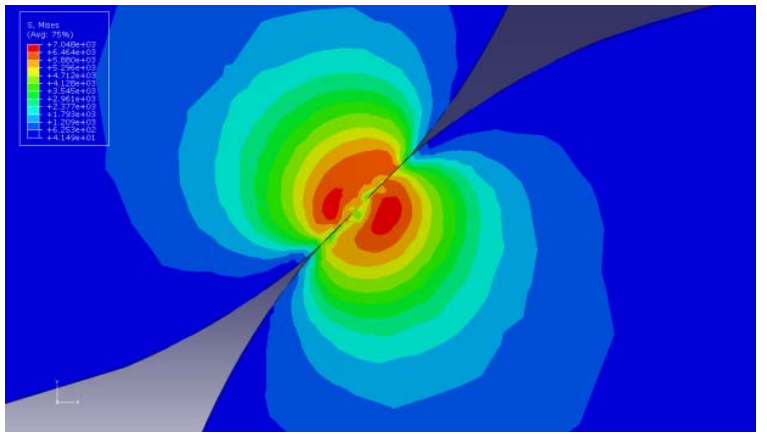

(b)

Figure 8. Von Mises stress contours at the contact points for (a) QS and (b) BCC models.

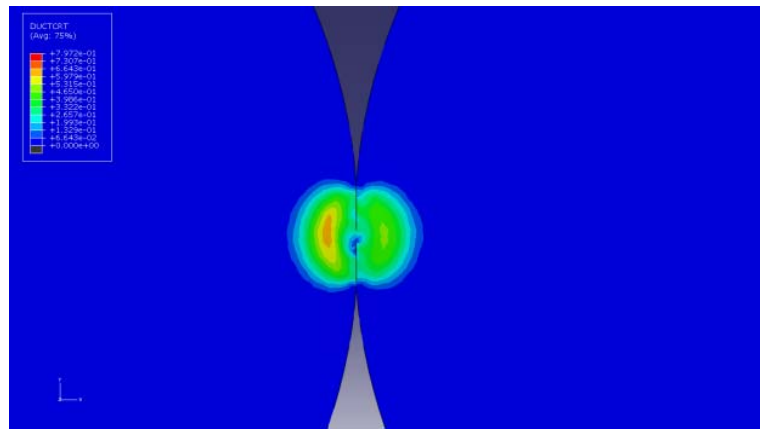

(a)

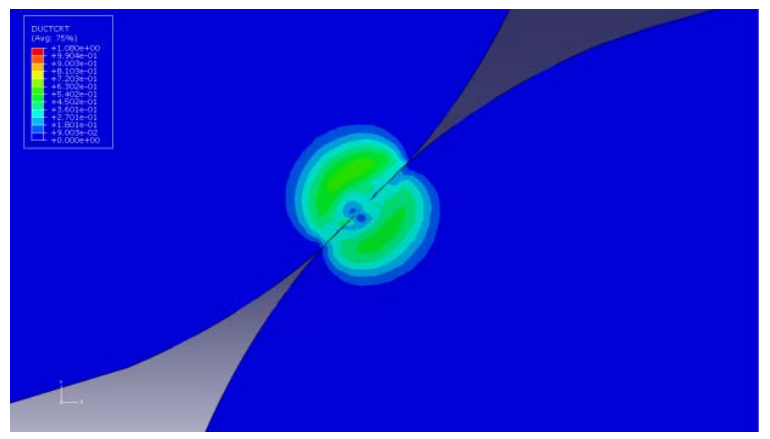

(b)

Figure 9. Damage contours at the contact points for (a) QS and (b) BCC models. 


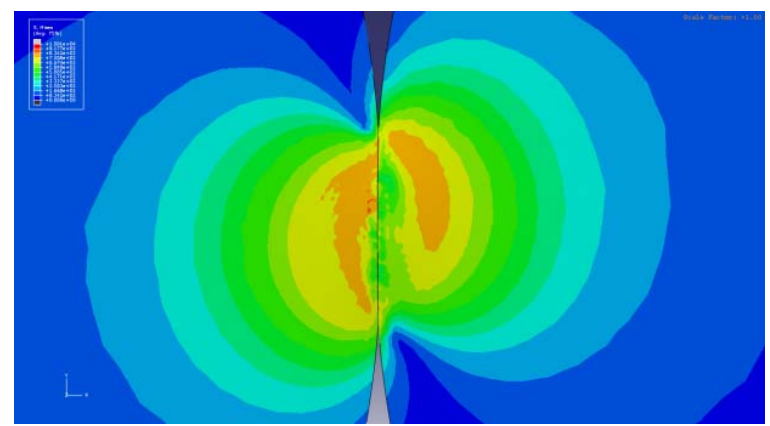

(a)

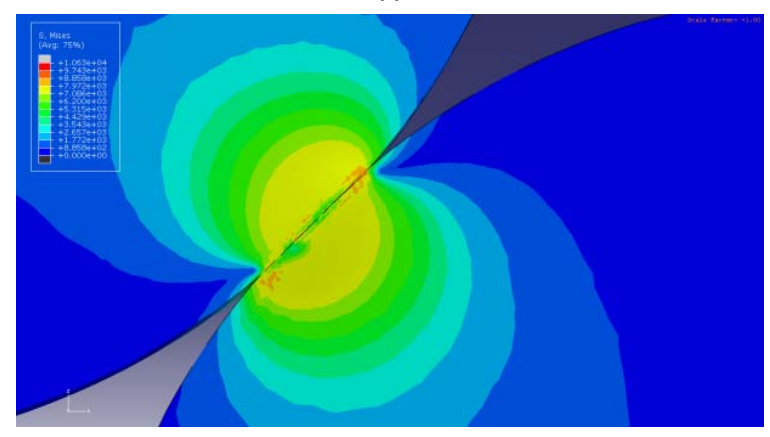

(b)

Figure 10. Von Mises stress contours at the contact points for (a) QS and (b) BCC models.

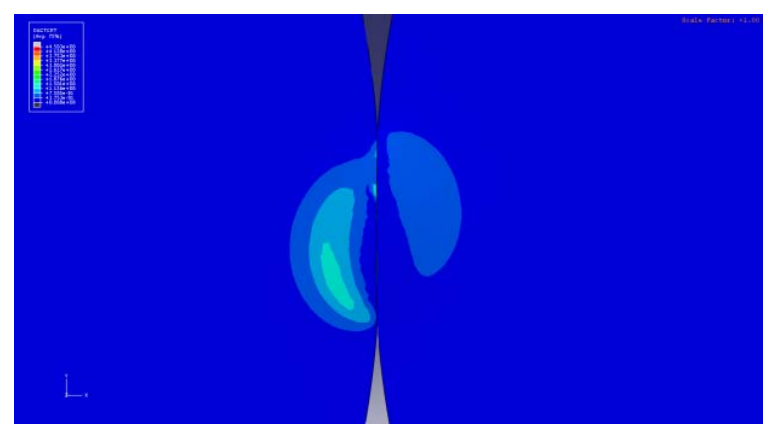

(a)

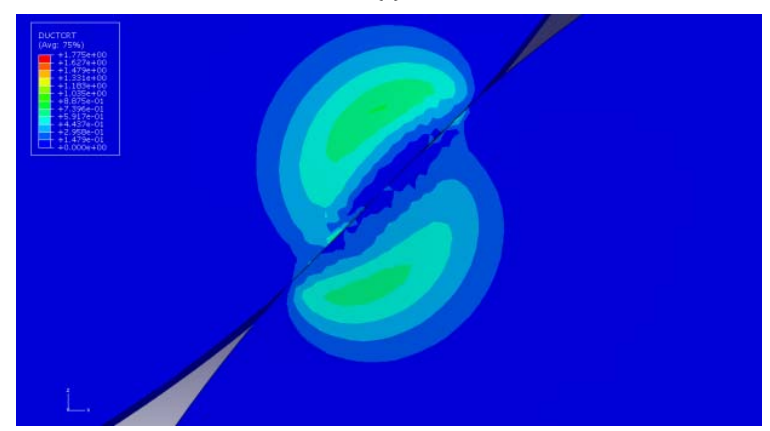

(b)

Figure 11. Damage contours at the contact points for (a) QS and (b) BCC models.
Table 3. Mass removal prediction.

\begin{tabular}{ll}
\hline Sinulation Model & $\begin{array}{l}\text { Mass } \\
\left(\mathrm{g} \mathrm{yr}^{-1}\right)\end{array}$ \\
\hline Static QS & 0.0 \\
Static BCC & 5.9 \\
Dynamic QS & 6.5 \\
Dynamic BCC & 6.7 \\
Cogliati's Results & 4.0 \\
(Cogliati and Ougouag, 2010) & \\
\hline
\end{tabular}

In the dynamic simulation which was a more realistic one, the QS model mass removal estimate was $6.5 \mathrm{~g} \mathrm{yr}^{-1}$, while it was $6.7 \mathrm{~g} \mathrm{yr}^{-1}$ for the BCC model. Table 3 shows a comparison between the results of the current model and those by Cogliati (2010).

The dust production estimate of 6.5 to 6.7 grams per year is very low compared to an estimated of $3 \mathrm{~kg}$ per year in the German AVR (Moormann, 2009).

There are a number of reasons which make the present initial estimate more reliable as compared to AVR observations. The main reason there is a difference of three orders of magnitude between our results and that of AVR is that in this dust production prediction model, only pebble-pebble contacts are considered while, as mentioned earlier, there are a number of sources to graphite dust generation (Cogliati and Ougouag, 2010).

Another influential factor is the material properties; while temperatures of about $900{ }^{\circ} \mathrm{C}$ are experienced in a PBR, the only material parameters available at this point are at room temperature from (Yokoyama et al., 2008). Also, it is uncertain how much of the dust produced in AVR, was a result of mechanical wear, as opposed to other sources. The dust production in AVR was observed by annually removing the filter and measuring the amount of dust, which is generated from different sources such as oil ingress, air ingress, metallic components and pebble handling.

\section{Conclusions}

The advantage of performing numerical analyses is to achieve an estimate of the mass of graphite removed per working year of an NGNP during its service period. This order of magnitude of estimate can be an approximate input for safety design of PBRs. This estimate is a good agreement with those in the literature. However, more investigations are in progress to enhance the accuracy of the prediction of dust generation in PBRs. Considering a wear model to calculate the wear mass based on the contact normal forces leads to results of higher accuracy and dependability. Performing simulations for various pebble-pebble configurations can also lead to better evaluation the wear mass. 
Acknowledgements. Thanks are due to different people who have been of various sorts of help. At University of Idaho the following people were of continuous assistance: Ahmad Abdelnabi, Bryan Riga and Karl Rink. The authors acknowledge the contributions of Abderrafi Ougouag and Joshua J. Cogliati at Idaho National Lab. This project, NEUP-90151, is supported by DOE.

Edited by: A. Barari

Reviewed by: A. Siahpush and A. Rezania

\section{References}

ABAQUS FEA: SIMULIA web site, Dassault Systèmes, www. simulia.com, last access: May 2010.

Cogliati, J. and Ougouag, A. M.: Pebble Bed Reactor Dust Production Model, Proceedings of ASME 4th International Topical Meeting on High Temperature Reactor Technology, HTR200858289, available at: http://www.inl.gov/technicalpublications/ Documents/4074915.pdf, 2008.

Cogliati, J. J. and Ougouag, A. M.: Dust Production Model for HTR-10, INL Report, 2010.

IAEA: Evaluation of High Temperature Gas Cooled Reactor Performance: Benchmark Analysis Related to Initial Testing of the HTTR and HTR-10, IAEA-TECDOC-1382, 2003.
Johnson, G. R. and Cook, W. H.: Fracture Characteristics of Three Metals Subjected to Various Strains, Strain rates, Temperatures and Pressures, Eng. Fract. Mech., 21, 31-48, 1985.

Moormann, R.: A safety re-evaluation of the AVR pebble bed reactor operation and its consequences for future HTR concepts, JUEL-4275, retrieved 2 April 2009.

Schaffer, M. B.: Nuclear power for clean, safe and secure energy independence, Foresight, 9, 47-60, 2007.

du Toit, C. G., van Antwerpen, W., and Rousseau, P. G.: Analysis of the Porous Structure of an Annular Pebble Bed Reactor, Final Paper 9123, ICAPP, 2009.

US Nuclear Regulatory Commission: Next Generation Nuclear Plant Phenomena Identification and Ranking Tables (PIRTs), NUREG/CR-6944, Main Report, 2008.

Xiaowei, L., Suyaun, Y., Zhen-sheng, Z., and Shu-yan, H.: Estimation of Graphite Dust Quantity and Size Distribution of Graphite Particle in HTR-10, Nuclear Power Engineering, 26, 0258-0926, 2005.

Yoda, S. and Eto, M.: The tensile deformation behavior of nucleargrade isotropic graphite posterior to hydrostatic loading, J. Nucl. Mater., 118, 214-219, 1983.

Yokoyama, T., Nakai, K., and Futakawa, M.: Compressive StressStrain Characteristics of Nuclear-Grade Graphite IG-11: Effect of specimen size and strain rate, Journal of Japan Society of Nuclear, 7, 66-73, 2008. 